\title{
Pharmacokinetic Changes Secondary to Roux en Y Gastric Bypass
}

\section{Christopher Giuliano $^{1 *}$, Sheila M. Wilhelm² and Pramodini B. Kale-Pradhan ${ }^{1}$}

${ }^{1}$ Eugene Applebaum College of Pharmacy and Health Science, Department of Pharmacy Practice, Wayne State University, St. John Hospital and Medical Center, Detroit, MI 48201, USA

${ }^{2}$ Eugene Applebaum College of Pharmacy and Health Science, Department of Pharmacy Practice, Wayne State University, Harper University Hospital, Detroit, MI 48201, USA

\begin{abstract}
Objective: To review the influence of Roux-en-Y gastric bypass (RYGB) on pharmacokinetic parameters of medications.

Data sources: PubMed was searched from inception to September 2012 to identify studies. Search terms included bariatric surgery, gastric bypass, Roux-en-Y, pharmacokinetic, and absorption. Studies included for this review were limited to English language studies published in full.

Data synthesis: Obesity is a major health care concern and is on the rise. This has led to an increasing number of bariatric surgeries. Such procedures may have profound effects on pharmacokinetic parameters of many medications depending on the extent of surgical changes that are made. Surgical procedures such as RYGB are most likely to affect medication absorption. Factors that may affect medication absorption in RYGB patients include changes in intestinal or gastric $\mathrm{pH}$, surface area, intestinal metabolism and transport mechanisms. Published studies have been primarily conducted in RYGB patients and have shown varied effect on overall absorption of medications.

Conclusions: RYGB may have profound effects on medication absorption. Predicting absorption is difficult due to interplay of several factors including, changes in intestinal surface area, intestinal metabolism, efflux pumps, active transporters and gastrointestinal $\mathrm{pH}$. Future studies are needed, particularly studies evaluating medications that have a low bioavailability and are commonly used in the bariatric surgery population.
\end{abstract}

Keywords: Roux en Y gastric bypass; Gastric; Intestine; Tmax; Cmax

\section{Introduction}

Obesity is a growing epidemic leading to world-wide public health concerns. In $1999-2000,27.5 \%$ of men and $33.4 \%$ of women were obese [1]. The prevalence increased to $35.5 \%$ in men and $35.8 \%$ in women by 2009-2010 [1]. Bariatric surgery is an excellent option for patients with clinically severe obesity, defined as body mass index (BMI) of greater than 40 or BMI of $>35$ with serious comorbid conditions [2]. The number of bariatric surgical procedures has increased from approximately 13,000 in 1998 to over 121,000 in 2004 in the United States $[3,4]$. There are three types of procedures that are typically employed to address the issue of obesity including restrictive, malabsorptive and restrictive-malabsorptive. Each of these procedures may affect medication absorption differently based on the anatomical changes that are made during surgery.

\section{Bariatric Procedures}

Restrictive procedures significantly reduce the gastric capacity and limit oral intake thereby producing weight loss [5]. Common restrictive procedures include vertical banded gastroplasty, adjustable gastric banding, and sleeve gastrectomy. Vertical banded gastroplasty is performed by introducing a vertical partition in the stomach at the gastro esophageal junction to produce a gastric pouch [3]. The stoma between the gastric pouch and the remainder of the stomach is reinforced with a band to prevent dilation of the opening. This procedure has fallen out of favor due to development of persistent vomiting or gastro esophageal reflux and an inflammatory response leading to scarring. Adjustable gastric banding is a procedure that involves placing an adjustable silicone band $1-2 \mathrm{~cm}$ below the gastro esophageal junction which creates a 20-30 milliliter (mL) upper gastric pouch [6]. The constriction of the band may be adjusted using a saline injection in to a subcutaneous port. This procedure is easily reversible and is increasing in popularity. Sleeve gastrectomy is a procedure where the greater curvature of the stomach is removed [7]. This procedure can be used alone or combined with biliopancreatic diversion.

Malabsorptive procedures modify the length of the intestines, which decreases absorption of nutrients. Jejunoileal or intestinal bypass is a surgical procedure that bypasses more than $90 \%$ of the small intestine without manipulating the stomach [3]. This is accomplished by forming a blind loop and connecting the proximal jejunum to the terminal ileum. This procedure has fallen out of favor because of related complications including metabolic issues, hepatic failure, nephrolithiasis and autoimmune complications.

Restrictive-malabsorptive procedures such as Roux-en-Y gastric bypass (RYGB) and biliopancreatic diversion combine both of these approaches. The RYGB is one of the more common gastric bypass procedures and has been the focus of trials effecting medication absorption [4]. It involves dividing the stomach to form a gastric pouch

*Corresponding author: Christopher Giuliano, Pharm. D, Assistant Professo (Clinical), Eugene Applebaum College of Pharmacy and Health Science, Department of Pharmacy Practice, Wayne State University, 259 Mack Avenue Detroit, MI 48201, USA, Tel: (313) 343-4427; Fax: (313) 343-7632; E-mail: ek2397@wayne.edu

Received September 21, 2012; Accepted October 17, 2012; Published October 19, 2012

Citation: Giuliano C, Wilhelm SM, Kale-Pradhan PB (2012) Pharmacokinetic Changes Secondary to Roux en Y Gastric Bypass. Adv Pharmacoepidem Drug Safety S1:001. doi:10.4172/2167-1052.S1-001

Copyright: (c) 2012 Giuliano C, et al. This is an open-access article distributed under the terms of the Creative Commons Attribution License, which permits unrestricted use, distribution, and reproduction in any medium, provided the original author and source are credited. 


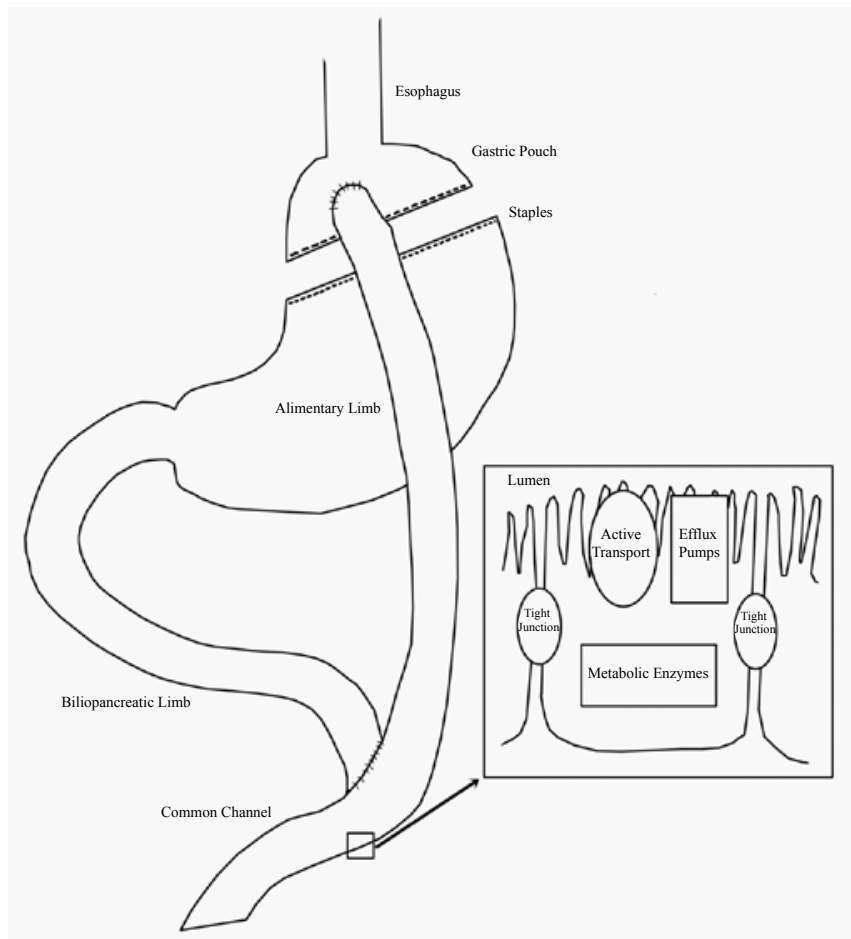

Figure 1: Roux-en-Y Gastric Bypass and factors that may influence medication absorption.

with a capacity of 15 to $30 \mathrm{~mL}[3,6]$. The jejunum is joined to the gastric pouch to form a gastro jejunaanastamosis. This portion of the small intestine is the alimentary limb. The biliopancreatic limb includes the duodenum and a portion of the jejunum which is joined to the distal jejunum to form a jejunojenjunostomy. The common channel is the portion of the small intestine distal to the jejunojejunostomy. Biliary and pancreatic secretions deposit in the common channel allowing for nutrient digestion and absorption. The length of the common channel is a factor which determines the extent of absorption of nutrients (Figure 1). Biliopancreatic diversion is a procedure similar to the RYGB; however, it involves a partial gastrectomy rather than a division of the stomach. In addition, the biliopancreatic limb is diverted further distally than in RYGB. This produces a shorter common channel and a greater restriction of nutrient absorption. This review will examine the pharmacokinetic changes following restrictive malabsorptive procedures, with a specific focus on Roux-en-Y gastric bypass (RYGB).

\section{Pharmacokinetic changes after bariatric surgery}

Several factors that can affect medication pharmacokinetics may be altered after bariatric surgery. These changes are dependent on the type of surgical procedures. Restrictive procedures result in a decreased volume available for oral intake, including medications. This is particularly concerning for patients taking multiple medications with a large pill burden. Gastric residence time may be variable in RYGB but decreased in sleeve gastrectomy [8-10]. An increase in gastric residence time may allow medications to be released slowly and increase absorption for medications that undergo uptake by a saturable transport mechanism [11]. Also, reduced gastric volume may decrease dissolution of medications. Some restrictive procedures such as sleeve gastrectomy and RYGB will decrease or bypass the available parietal cells and therefore reduce available gastric acid leading to increases in gastric $\mathrm{pH}[12]$. After the procedure, the normal $\mathrm{pH}$ of the stomach is expected to approximate the intestinal $\mathrm{pH}$ [13]. This may cause medications that are weak acids, such as acetylsalicylic acid, to become more ionized, hindering absorption. Ionized moieties are less likely to undergo passive diffusion across the gastrointestinal tract. Weak bases will either remain unchanged or have a small increase in absorption depending on the $\mathrm{pKa}$ of the medication.

A major cause of decreased absorption in patients with bariatric surgery is reduced gastrointestinal surface area. The portion of the small intestine bypassed determines the effect on absorptive capacity. Moving from the duodenum to the ileum, the absorptive capacity of the small intestines decreases where as the transit time increases [2]. Although the proximal small intestine has the highest absorptive capacity, it has the shortest transit time. This may result in less overall absorption proximally compared to distal small intestines. Procedures that bypass the duodenum and proximal jejunum such as RYGB may have less of an impact on absorption compared to procedures that bypass the jejunum and the majority of the ileum such as with the jejunoileal bypass. Also, medication absorption may be dependent on passive diffusion, active transport, paracellular transport, intracellular metabolism, efflux, and enterohepatic recirculation.

Passive diffusion relies on medication lipophilicity and concentration of medication in solution within the intestinal lumen relative to systemic concentration. Passive diffusion may occur anywhere along the small intestine, and to a lesser extent in the colon. The partition coefficient or Log P compares a medication's preference to be in a hydrophobic environment such as octanol to a hydrophilic environment such as water [13]. Therefore, the higher the Log P of a medication, the more lipophilic and less soluble it is. Optimal $\log \mathrm{P}$ values to facilitate both dissolution and passive diffusion are approximately 1-2 [14].

Unlike passive diffusion, active transport pumps facilitate movement of medication across intestinal cell membranes. Organic anion transporting polypeptides (OATP2B1 and OATP1A2), monocarboxylic acid transporter 1 (MCT1), and olligopeptide transporter (PEPT1) are active transport pumps found primarily in the duodenum and jejunum [13]. Plasma membrane monoamine transporter (PMAT) is a transport pump with unknown distribution in the small intestines [15]. Medications with small molecular weight may undergo paracellular transport via tight junctions, although this process is saturable.

Intracellular enzymes such as CYP3A, CYP2C9, CYP2C19, CYP2D6, phase 1 and 2 enzymes, uridinediphosphate, glucoronosyltransferases (UGT), phenylsulfotransferases (PST), and glutathione S-transferases (GST), are prevalent in the proximal small intestine and play a role in the metabolism of medications as they are absorbed [16]. Of the intestinal CYP enzymes, CYP3A4 is the most prevalent and accounts for more than $80 \%$ of intestinal CYP activity [17]. Some medications require enzymatic effects to be converted to their systemically active metabolite while others become inactivated by these enzymes. Medications may also be affected by the efflux pumps such as P-glycoprotein (PgP), breast cancer resistance protein (BCRP) and multidrug resistance associated protein 2 (MRP2) at the apical membrane of intestinal epithelial cells. These pumps transport intracellular molecules back into the intestinal lumen thereby reducing systemic absorption. PgP concentration increases as substances move from the duodenum to the ileum, which may decrease medication absorption following RYGB [18].

Medications that undergo enterohepatic recirculation are repeatedly exposed to the gastrointestinal tract [19]. In a non-surgical patient, a medication enters the gastrointestinal tract and is systemically absorbed. A portion of the systemically absorbed medication enters the 


\begin{tabular}{|c|c|c|c|c|c|c|c|c|}
\hline Medication & pKa & $\begin{array}{l}\text { Lipophilicity } \\
(\log P)\end{array}$ & Intestinal metabolism & Efflux pump & $\begin{array}{l}\text { Active transport } \\
\text { pumps }\end{array}$ & $\begin{array}{l}\text { Enterohepatic } \\
\text { recirculation }\end{array}$ & Tmax (hr) & Bioavailability \\
\hline $\begin{array}{l}\text { Sertraline } \\
{[26,27,38]}\end{array}$ & 8.5 & 4.8 & $\begin{array}{l}\text { CYP2C19 } \\
\text { CYP2D6 }\end{array}$ & $\mathrm{PgP}$ & No & No & $4-6$ & $44 \%^{a}$ \\
\hline $\begin{array}{l}\text { Azithromycin } \\
{[39,40]}\end{array}$ & 8.74 & 4 & No & $\begin{array}{l}\mathrm{PgP} \\
\text { MRP2 }\end{array}$ & No & No & $2-3$ & $37 \%$ \\
\hline $\begin{array}{l}\text { Atorvastatin } \\
{[26,32,41,42]}\end{array}$ & 4.46 & $\begin{array}{l}\text { 1.53-acid } \\
\text { 4.2-lactone }\end{array}$ & $\begin{array}{l}\text { CYP3A4 } \\
\text { GST } \\
\text { UGT }\end{array}$ & $\begin{array}{l}\text { PgP } \\
\text { BRCP, MRP-2 }\end{array}$ & $\begin{array}{l}\text { OATPB1OATPB3 } \\
\text { MCT }\end{array}$ & No & 2 & $14 \%$ \\
\hline $\begin{array}{l}\text { Metformin } \\
{[15,26,43]}\end{array}$ & 11.5 & -1.43 & No & No & $\begin{array}{l}\text { PMAT } \\
\text { OCT1 OCT3 }\end{array}$ & No & $3 c$ & $55 \%$ \\
\hline $\begin{array}{l}\text { Tacrolimus } \\
{[35,44],[26]}\end{array}$ & 14.07 & 2.7 & CYP3A4 & $\mathrm{PgP}$ & No & No & $0.5-1$ & $25 \%(5-93 \%)$ \\
\hline $\begin{array}{l}\text { Sirolimus } \\
{[26,34,45]}\end{array}$ & 13.37 & 6 & CYP3A4 & $\mathrm{PgP}$ & No & No & $0.5-3$ & $15 \%^{d}$ \\
\hline $\begin{array}{l}\text { MycophenolateMofetil } \\
{[26,46,47]}\end{array}$ & 15.67 & 3.2 & UGT & $\begin{array}{l}\text { MRP-2 } \\
\text { PgP }\end{array}$ & No & Yes & $1-2$ & $80.7-94 \%{ }^{\text {e }}$ \\
\hline
\end{tabular}

$a=$ Not determined in humans, $b=\log D$ values at ph of 7.4, $c=$ immediate release, $d=$ solution, e=Non enteric-coated, CYP=Cytochrome $P 450$, UGT=uridinediphosphateg lucoronosyltransferases, PST=phenylsulfotransferases, GST=glutathione S-transferases PgP=P-glycoprotein, BCRP=breast cancer resistance protein, MRP2=multidrug resistance associated protein, OATP=Organic anion transporting polypeptides, MCT1=monocarboxylic acid transporter 1, PEPT-1=peptide transporter 1, Plasma membrane monoamine transporter (PMAT)

Table 1: Pharmacokinetic properties of medications in Roux-en-Y gastric Bypass Studies.

liver and is partitioned into the bile where it re-enters the duodenum for repeated absorption [20]. PostRYGB, the medication will be exposed to reduced surface area resulting in decreased initial and repeated absorption. Serum bile acid concentrations may be increased in RYGB patients [21]. Certain medications such as lovastatin and pravastatin have shown increased absorption with increasing concentrations of bile acids [22,23]. However, bile acids are not in high concentrations in the alimentary limb so the overall effect is unclear.

Overall the above mechanisms work individually or in combination to affect medication absorption. The interplay of these mechanisms makes it difficult to predict the effect of RYGB on the absorption of medications. This review will examine the available literature regarding RYGB and pharmacokinetic changes and in particular medication absorption.

\section{Literature review}

A search of PubMed from inception to September 2012 was conducted using the following key terms: bariatric surgery, gastric bypass, Roux-en-Y, pharmacokinetic, and absorption. Studies included for this review were limited to english language studies published in full. Bibliographies of recent relevant articles were hand searched to identify any additional studies. We found a total of 5 pharmacokinetic studies evaluating 7 medications in our literature search. These trials focused on both commonly used medications (sertraline, azithromycin, atorvastatin, met form) and narrow therapeutic index medications (tacrolimus, sirolimus, and mycophenolatemofetil). Specific properties that may have an effect on absorption of these medications are presented in Table 1.

In a prospective, case controlled study of sertraline pharmacokinetics, five subjects who had undergone RYGB 9-15 months prior to enrollment were matched with five non RYGB subjects for gender, age and BMI [24]. Subjects were excluded from the study if they were found to be ultra-rapid or poor metabolizers for the CYP2D6 or 2C19 metabolic enzymes or were receiving any medication that is known to interact with sertraline. The primary endpoint was sertraline area under the curve (AUC) from 0-10.5 hours after oral ingestion of a single dose of sertraline $100 \mathrm{mg}$. Secondary endpoints were time to peak plasma level (Tmax) and maximum plasma concentration (Cmax). The RYGB and non-surgical groups were well matched for age (mean age 45.4 and 44.6 years, respectively) and BMI (29.9 and $30.6 \mathrm{~kg} /$ $\mathrm{m}^{2}$, respectively). The mean AUC from 0-10.5 hours was significantly lower in the RYGB group compared to the non-surgical group (124.4 ng-hr/mL vs. $314.8 \mathrm{ng}-\mathrm{hr} / \mathrm{ml}$, respectively, $p=0.043)$. The Cmax was also significantly less in the RYGB group compared to the non-surgical group (19 ng/mL vs. $48.7 \mathrm{ng} / \mathrm{mL}$, respectively, $p=0.043$ ) but the Tmax was not significantly different ( $3.9 \mathrm{hr} v s .3 .4 \mathrm{hr}$, respectively, $p=0.357$ ). Overall, this study was well conducted, although a longer evaluation of the AUC may have been more appropriate.

These changes may be partially predicted when assessing pharmacokinetic properties of sertraline. First, sertraline is a weak base with a $\mathrm{pKa}$ of 8.5 and exists primarily in the ionized state in the small intestine. RYGB should not affect the degree of ionization of sertraline. Due to its ionized state, sertraline likely requires active transport for absorption, although no active transporters have been identified. Secondly, in a simulated environment, sertraline undergoes significantly greater dissolution in a normal environment versus a RYGB environment ( $16 \%$ dissolved $v s .10 \%$ dissolved, $p<0.04$ ) [25]. As the $\log \mathrm{P}$ value increases, solubility of medications decrease. A Log P of 4.8 in this situation reinforces that medication absorption is limited by its solubility [26]. Lastly, sertraline undergoes CYP2C19 and to a smaller degree of CYPD6 metabolism in the gut and also PgP excretion [27]. CYP2C19 and CYP2D6 concentrations decrease as sertraline moves from the stomach to terminal ileum while PgP increases $[18,28]$. In an RYGB patient, this could lead to increased absorption as some intestinal metabolism is bypassed; however, the length of intestine likely plays a more important role as gastrointestinal CYP2C19 and especially CYP2D6 have limited impact on sertraline metabolism.

A prospective pharmacokinetic study of azithromycin was completed in 14 female patients who had undergone RYGB compared to 14 female non-surgical patients who were matched for BMI [29]. Enrolled patients were administered azithromycin $500 \mathrm{mg}$ orally followed by plasma azithromycin sampling. The primary endpoint was the azithromycin AUC from 0-24 hours. Secondary outcomes were Cmax and Tmax. In the RYGB and non-surgical groups, mean age (44.1 years vs. 44.5 years, respectively, $p=0.93)$ and BMI $\left(36.8 v s .35 .9 \mathrm{~kg} / \mathrm{m}^{2}\right.$, respectively, $p=0.98$ ) were similar between the two groups. AUC was significantly lower in subjects who had undergone RYGB compared to non-surgical subjects ( 1.41 vs. $2.07 \mathrm{mg}$-hr/L, respectively, $p=0.008$ ). 
Cmax was similar between the RYGB and nonsurgical groups $(0.26$ vs. $0.363 \mathrm{mg} / \mathrm{dL}$, respectively, $p=0.08)$ as was the Tmax (2.14 vs. 2.36 hours, respectively, $p=0.75$ ).

These changes may be partially predicted by the pharmacokinetic properties of azithromycin. Azithromycin is a weak base with a similar pKa and $\log \mathrm{P}$ to sertraline, therefore its solubility will be a limiting factor in its absorption [26]. Azithromycin will be more likely to exist in its ionized state in the less acidic gastrointestinal tract following RYGB given its $\mathrm{pKa}$. This hinders its passive diffusion, and an active transport mechanism for azithromycin has not been identified. Azithromycin is a substrate for the PgP efflux pumps, which are most prevalent in the distal small intestine and into the colon [30]. Following RYGB, azithromycin will be exposed to areas of high intestinal PgP activity which, when combined with reduced surface area, results in an overall decrease in systemic bioavailability.

The effects of RYGB on the pharmacokinetic parameters of atorvastatin were investigated in 12 patients (66\% female, mean age 52 years) who were going to undergo RYGB [31]. Subjects who were scheduled for RYGB were eligible for the study if they were being treated with atorvastatin $20-80 \mathrm{mg}$ daily (mean dose $37 \mathrm{mg}$ daily). Atorvastatin kinetic evaluations were completed the day prior to surgery and again three to six weeks following surgery. The mean AUC from 0-8 hours did not significantly differ from prior to post RYGB (75 vs. $50 \mathrm{ng}$-hr/ $\mathrm{ml}$, respectively, $p=0.99)$. Cmax and Tmax were also similar at both time points (Cmax $28 \mathrm{ng} / \mathrm{ml} v s .13 \mathrm{ng} / \mathrm{ml}$, respectively, $p=0.83$; Tmax $1.6 \mathrm{hr} v s .1 .8 \mathrm{hr}$, respectively, $p=0.39$ ). The authors assessed the results for the patients with the highest and lowest systemic availability prior to surgery. The three patients with the highest AUC prior to surgery experienced a significant reduction post RYGB (median ratio of AUC $0.4, p=0.01$ ) whereas the nine patients with the least AUC prior to surgery experienced a significant increase in AUC following RYGB (median ratio of AUC 1.2, $p=0.03$ ). This study is limited by the time frame used to assess pharmacokinetic changes. Patients had very recently undergone RYGB, and pharmacokinetic changes may vary as more time passes.

Atorvastatin converts to either acidic or lactone forms which make it both highly soluble and readily absorbed across the gastrointestinal tract [32]. Despite both high solubility and absorption, atorvastatin displays a bioavailability of $14 \%$ because of first pass metabolism in the liver and intestine as well as excretion by a variety of efflux pumps. Although atorvastatin undergoes active transport, this is unlikely to play a large role in its absorption [32]. Changes seen in this study may be explained by inter-individual variability in intestinal CYP3A4 metabolism. Intestinal CYP3A4 levels can vary up to a 20 fold [17]. In an individual with intrinsically low intestinal CYP3A4 activity, the loss of CYP3A4 exposure after surgery may not have a large effect on absorption, and rather, surface area may have a significant impact on medication absorption. Conversely, an individual with intrinsically high intestinal CYP3A4 activity may have an increase in absorption of atorvastatin because less medication will be metabolized in the small intestines.

A prospective, nonblinded trial assessed the pharmacokinetic parameters of metformin in 16 non-diabetic RYGB patients and 16 non-surgical patients matched for age (mean age 40.2 years) and BMI (mean BMI $39.2 \mathrm{~kg} / \mathrm{m}^{2}$ ) [11]. The primary endpoint was the AUC of metformin from time zero extrapolated to infinity $(0-\infty)$. The secondary outcomes were Cmax, Tmax, bioavailability estimated from metformin excretion in the urine over 24 hours, and AUC of metformin from 0-24 hours. Nearly the entire bioavailable dose of metformin is eliminated within 24 hours; therefore, unlike most medications, 24 hour urinary excretion can be used to reliably estimate bioavailability without a required intravenous dose. The AUC $0-\infty$ was similar between the two groups, $13.7 \mathrm{mcg}-\mathrm{hr} / \mathrm{ml}$ for RYGB subjects compared to $11.4 \mathrm{mcg}-\mathrm{hr} /$ $\mathrm{ml}$ for non-surgical patients $(p=0.2)$. The Cmax was $2 \mathrm{mcg} / \mathrm{ml}$ versus $1.8 \mathrm{mcg} / \mathrm{ml}$ for RYGB and control, respectively $(p=0.32)$. Tmax was 3 hours in both groups $(p=0.89)$. The estimated bioavailability was significantly higher in the RYGB group compared to control (41.8\% vs. $27.8 \%, p=0.007)$. The AUC from $0-24$ hours was 13.4 and $11.1 \mathrm{mcg}-\mathrm{hr} /$ $\mathrm{ml}$, respectively $(p=0.2)$.

Pharmacokinetic properties of metformin partially explain the changes in AUC observed in the study. Metformin is a weak base with a $\mathrm{pKa}$ of 11.5 , which exists primarily in a cationic state in the gastrointestinal tract. Its $\log \mathrm{P}$ value of -1.43 also indicates that metformin has poor lipophilicity and will be unable to easily cross the gastrointestinal membrane. Both of these factors indicate that metformin likely undergoes active transport to be absorbed. PMAT and organic cation transporters 1 and 3 play a role in the absorption of metformin in the intestines with PMAT playing the most substantial role [15]. PMAT is a saturable transporter in the small intestine and may be a rate limiting step in the absorption of metformin. In RYGB patients gastric residence time will be increased allowing for slower release of metformin into the small intestine. This will result in less saturation of PMAT, which may lead to an increase in absorption.

In a pilot study of six patients who had undergone RYGB between 2 months and 7.41 years prior to the trial, pharmacokinetics of mycophenolatemofetil (MMF), sirolimus and tacrolimus were assessed [33]. Four of the six included patients had end stage renal disease requiring dialysis and were awaiting transplant. These patients received 24 hours of immunosuppressive therapy with MMF, sirolimus and tacrolimus. Two of the six patients had undergone renal transplant and were maintained on their immunosuppressive regimens. The kinetic parameters after the second dose of MMF in the three end stage renal disease patients with reported data included a mean AUC from 0-12 hours of $907.4 \mathrm{mcg}-\mathrm{hr} / \mathrm{L}$, a mean Cmax of $67.2 \mathrm{mcg} / \mathrm{L}$, and a mean Tmax of 6.7 hours. For the two post-transplant patients, mean AUC from 0-12 hours was $903.9 \mathrm{mcg}$-hr/L, mean Cmax was $69.8 \mathrm{mcg} / \mathrm{L}$, and mean Tmax was 2.5 hours. The kinetic parameters after a single dose of sirolimus in the four end stage renal disease patients were a mean AUC from 0-24 hours of $145.7 \mathrm{mcg}-\mathrm{hr} / \mathrm{L}$, AUC from 0 - $\infty$ of $181.1 \mathrm{mcg}-\mathrm{hr} / \mathrm{L}$, a mean Cmax of $18.2 \mathrm{mcg} / \mathrm{L}$, and a mean Tmax of 1.8 hours. Sirolimus was not assessed in the post-transplant patients. The kinetic parameters after the second dose of tacrolimus in the three end stage renal disease patients with reported data included a mean AUC from 0-12 hours of $58.8 \mathrm{mcg}-\mathrm{hr} / \mathrm{L}$, a mean Cmax of $12.3 \mathrm{mcg} / \mathrm{L}$, and a mean Tmax of 3.3 hours. For the one post-transplant patient receiving tacrolimus, AUC from 12-24 hours was $63.8 \mathrm{mcg}-\mathrm{hr} / \mathrm{L}$, Cmax was $16 \mathrm{mcg} / \mathrm{L}$, and mean Tmax was 1 hour. The study design did not include a comparator group of patients who had not undergone RYGB, which makes it difficult to draw conclusions about the potential changes in pharmacokinetic parameters due to RYGB. As well only six patients were enrolled in the study and not all were evaluable.

Pharmacokinetic changes in this study are difficult to predict due to the above mentioned limitations. Both tacrolimus and sirolimus have a wide variability in non-surgical patients and this may be more pronounced in RYGB patients [34,35]. Both medications have similar pKa's and will exist primarily in the ionized state, although the higher log $P$ value for sirolimus may indicate less solubility than tacrolimus. Both medications are substrates for PgP efflux pumps and CYP3A4 intestinal 
metabolism. Similar to atorvastatin, absorption may be variable due to amounts of intestinal CYP3A4. Overall, the pharmacokinetic profiles suggest that there may be no change or a reduction in systemic bioavailability of sirolumus and tacrolimus.

MMF is an ester prodrug, which is quickly hydrolyzed in the gastrointestinal tract, blood, tissues, and liver to its active metablolitemycophenolic acid (MPA) [36]. MPA undergoes glucornidation by UGT in the small intestines, liver, and kidney and is also excreted by MRP-2 and PgP. UGT content is highest in the jejunum and ileum, which would not be affected by RYGB [37]. MPA also undergoes enterohepatic recirculation, exposing the shortened length of the intestine to the medication repeatedly. This aids in absorption, but to a lesser degree than it would in a patient with an intact gastrointestinal tract and greater available intestinal surface area. All of these changes would lead to an expected decrease in absorption for MMF following RYGB, which was observed in this study compared to historical controls.

\section{Conclusion}

Obesity is an epidemic that is receiving increasing attention as associated health issues are becoming more prevalent and we seek ways to effectively address these issues. Bariatric surgery and specifically RYGB is being used more commonly to treat obesity. Making significant changes to the gastrointestinal tract has ramifications on medication absorption. There are many factors that affect medication absorption including medication-specific characteristics such as $\mathrm{pKa}$ and Log P. In addition, patient specific factors such as expression of intestinal metabolic enzymes can affect medication absorption. Surgical changes to the gastrointestinal tract affect medication absorption through $\mathrm{pH}$ alteration, increased or decreased gastric residence time, surface area reduction, and altered exposure to metabolic enzymes and efflux pumps. Some of these changes may have a predictable effect on the absorption of a specific medication given its pharmacokinetic parameters; however it is difficult to accurately predict absorption following RYGB due to the considerable interplay of these factors. In order to most effectively and safely treat patients that undergo RYGB, studies are needed to assess changes in absorption of medications in this population, particularly for medications with low bioavailability that are commonly used in the bariatric surgery population.

\section{References}

1. Ogden CL, Carroll MD, Kit BK, Flegal KM (2012) Prevalence of Obesity in the United States, 2009-2010.

2. National Institutes of Health, National Heart, Lung and Blood Institute, North American Associaton for the Study of Obesity. (2000) The Practical Guide: Identification, Evaluation, and Treatment of Overweight and Obesity in Adults.

3. Elder KA, Wolfe BM (2007) Bariatric surgery: a review of procedures and outcomes. Gastroenterology 132: 2253-2271.

4. Samuel I, Mason EE, Renquist KE, Huang YH, Zimmerman MB, et al. (2006) Bariatric surgery trends: an 18-year report from the International Bariatric Surgery Registry. Am J Surg 192: 657-662.

5. Ashy AR, Merdad AA (1998) A prospective study comparing vertical banded gastroplasty versus laparoscopic adjustable gastric banding in the treatment of morbid and super-obesity. Int Surg 83: 108-110.

6. Abeles D, Shikora SA (2008) Bariatric surgery: current concepts and future directions. Aesthet Surg J 28: 79-84.

7. Zinzindohoue F, Chevallier JM, Douard R, Elian N, Ferraz JM, et al. (2003) Laparoscopic gastric banding: a minimally invasive surgical treatment for morbid obesity: prospective study of 500 consecutive patients. Ann Surg 237: $1-9$

8. Suzuki S, Ramos EJ, Goncalves CG, Chen C, Meguid MM (2005) Changes in
GI hormones and their effect on gastric emptying and transit times after Rouxen-Y gastric bypass in rat model. Surgery 138: 283-290.

9. Ardila-Hani A, Soffer EE (2011) Review article: the impact of bariatric surgery on gastrointestinal motility. Aliment Pharmacol Ther 34: 825-831.

10. Wang G, Agenor K, Pizot J, Kotler DP, Harel Y, et al. (2012) Accelerated gastric emptying but no carbohydrate malabsorption 1 year after gastric bypass surgery (GBP). Obes Surg 22: 1263-1267.

11. Padwal RS, Gabr RQ, Sharma AM, Langkaas LA, Birch DW, et al. (2011) Effect of gastric bypass surgery on the absorption and bioavailability of metformin Diabetes Care 34: 1295-1300.

12. Gubbins PO, Bertch KE (1991) Drug absorption in gastrointestinal disease and surgery. Clinical pharmacokinetic and therapeutic implications. Clin Pharmacokinet 21: 431-447.

13. Smith A, Henriksen B, Cohen A (2011) Pharmacokinetic considerations in Roux-en-Y gastric bypass patients. Am J Health Syst Pharm 68: 2241-2247.

14. Lin JH, Lu AY (1997) Role of pharmacokinetics and metabolism in drug discovery and development. Pharmacol Rev 49: 403-449.

15. Zhou M, Xia L, Wang J (2007) Metformin transport by a newly cloned proton-stimulated organic cation transporter (plasma membrane monoamine transporter) expressed in human intestine. Drug Metab Dispos 35: 1956-1962.

16. Mechanick $\mathrm{JI}$ (2011) Bariatric surgery and the role of the clinical endocrinologist: 2011 update. Endocr Pract 17: 788-797.

17. Paine MF, Hart HL, Ludington SS, Haining RL, Rettie AE, et al. (2006) The human intestinal cytochrome P450 "pie". Drug Metab Dispos 34: 880-886.

18. Thörn M, Finnström N, Lundgren S, Rane A, Lööf L (2005) Cytochromes P450 and MDR1 mRNA expression along the human gastrointestinal tract. $\mathrm{Br} \mathrm{J}$ Clin Pharmacol 60: 54-60.

19. Padwal R, Brocks D, Sharma AM (2010) A systematic review of drug absorption following bariatric surgery and its theoretical implications. Obes Rev 11: 41-50.

20. Roberts MS, Magnusson BM, Burczynski FJ, Weiss M (2002) Enterohepatic circulation: physiological, pharmacokinetic and clinical implications. Clin Pharmacokinet 41: 751-790.

21. Patti ME, Houten SM, Bianco AC, Bernier R, Larsen PR, et al. (2009) Serum bile acids are higher in humans with prior gastric bypass: potential contribution to improved glucose and lipid metabolism. Obesity (Silver Spring) 17: 16711677.

22. Kim K, Yoon I, Chun I, Lee N, Kim T, et al. (2011) Effects of bile salts on the lovastatin pharmacokinetics following oral administration to rats. Drug Deliv 18: 79-83.

23. Chun IK, Lee KM, Lee KE, Gwak HS (2012) Effects of bile salts on gastrointestinal absorption of pravastatin. J Pharm Sci 101: 2281-2287.

24. Roerig JL, Steffen K, Zimmerman C, Mitchell JE, Crosby RD, et al. (2012) Preliminary comparison of sertraline levels in postbariatric surgery patients versus matched nonsurgical cohort. Surg Obes Relat Dis 8: 62-66.

25. Seaman JS, Bowers SP, Dixon P, Schindler L (2005) Dissolution of common psychiatric medications in a Roux-en-Y gastric bypass model. Psychosomatics 46: $250-253$

26. Cheng T, Zhao Y, Li X, Lin F, Xu Y, et al. (2007) Computation of octanol-water partition coefficients by guiding an additive model with knowledge. J Chem Inf Model 47: 2140-2148.

27. Wang JS, Zhu HJ, Gibson BB, Markowitz JS, Donovan JL, et al. (2008) Sertraline and its metabolite desmethylsertraline, but not bupropion or its three major metabolites, have high affinity for P-glycoprotein. Biol Pharm Bull 31 231-234.

28. Thelen K, Dressman JB (2009) Cytochrome P450-mediated metabolism in the human gut wall. J Pharm Pharmacol 61: 541-558.

29. Padwal RS, Ben-Eltriki M, Wang X, Langkaas LA, Sharma AM, et al. (2012) Effect of gastric bypass surgery on azithromycin oral bioavailability. J Antimicrob Chemother 67: 2203-2206.

30. Tachibana T, Kato M, Sugiyama $Y$ (2012) Prediction of nonlinear intestinal absorption of CYP3A4 and P-glycoprotein substrates from their in vitro $\mathrm{Km}$ values. Pharm Res 29: 651-668.

31. Skottheim IB, Stormark K, Christensen H, Jakobsen GS, Hjelmesaeth J, et 
Citation: Giuliano C, Wilhelm SM, Kale-Pradhan PB (2012) Pharmacokinetic Changes Secondary to Roux en Y Gastric Bypass. Adv Pharmacoepidem Drug Safety S1:001. doi:10.4172/2167-1052.S1-001

Page 6 of 6

al. (2009) Significantly altered systemic exposure to atorvastatin acid following gastric bypass surgery in morbidly obese patients. Clin Pharmacol Ther 86: 311-318

32. Lennernas H (2003) Clinical pharmacokinetics of atorvastatin. Clin Pharmacokinet 42: 1141-1160.

33. Rogers CC, Alloway RR, Alexander JW, Cardi M, Trofe J, et al. (2008) Pharmacokinetics of mycophenolic acid, tacrolimus and sirolimus after gastric bypass surgery in end-stage renal disease and transplant patients: a pilot study. Clin Transplant 22: 281-291.

34. Mahalati K, Kahan BD (2001) Clinical pharmacokinetics of sirolimus. Clin Pharmacokinet 40: 573-585.

35. Staatz CE, Tett SE (2004) Clinical pharmacokinetics and pharmacodynamics of tacrolimus in solid organ transplantation. Clin Pharmacokinet 43: 623-653.

36. Lee WA, Gu L, Miksztal AR, Chu N, Leung K, et al. (1990) Bioavailability improvement of mycophenolic acid through amino ester derivatization. Pharm Res 7: 161-166.

37. Shipkova M, Strassburg CP, Braun F, Streit F, Gröne HJ, et al. (2001) Glucuronide and glucoside conjugation of mycophenolic acid by human liver, kidney and intestinal microsomes. Br J Pharmacol 132: 1027-1034.

38. DeVane CL, Liston HL, Markowitz JS (2002) Clinical pharmacokinetics of sertraline. Clin Pharmacokinet 41: 1247-1266.

39. Sugie M, Asakura E, Zhao YL, Torita S, Nadai M, et al. (2004) Possible involvement of the drug transporters $\mathrm{P}$ glycoprotein and multidrug resistanceassociated protein Mrp2 in disposition of azithromycin. Antimicrob Agents Chemother 48: 809-814.
40. Lalak NJ, Morris DL (1993) Azithromycin clinical pharmacokinetics. Clin Pharmacokinet 25: 370-374.

41. Wu X, Whitfield LR, Stewart BH (2000) Atorvastatin transport in the Caco-2 cell model: contributions of P-glycoprotein and the proton-monocarboxylic acid cotransporter. Pharm Res 17: 209-215.

42. Goulas A, Kosmidou M, Hatzitolios Al, Molyva D, Fidani L, et al. (2008) Glutathione S-transferase null and cholesteryl ester transfer protein Taql B polymorphisms and lipid response to atorvastatin in Greek dyslipidaemic patients. Basic Clin Pharmacol Toxicol 102: 559-562.

43. Graham GG, Punt J, Arora M, Day RO, Doogue MP, et al. (2011) Clinical pharmacokinetics of metformin. Clin Pharmacokinet 50: 81-98.

44. Vicari-Christensen M, Repper S, Basile S, Young D (2009) Tacrolimus: review of pharmacokinetics, pharmacodynamics, and pharmacogenetics to facilitate practitioners' understanding and offer strategies for educating patients and promoting adherence. Prog Transplant 19: 277-284.

45. Lampen A, Zhang Y, Hackbarth I, Benet LZ, Sewing KF, et al. (1998) Metabolism and transport of the macrolide immunosuppressant sirolimus in the small intestine. J Pharmacol Exp Ther 285: 1104-1112.

46. Staatz CE, Tett SE (2007) Clinical pharmacokinetics and pharmacodynamics of mycophenolate in solid organ transplant recipients. Clin Pharmacokinet 46: 13-58.

47. Wang J, Figurski M, Shaw LM, Burckart GJ (2008) The impact of P-glycoprotein and Mrp2 on mycophenolic acid levels in mice. Transpl Immunol 19: 192-196.
This article was originally published in a special issue, Recent Trends in Pharmacokinetics/Pharmacodynamics handled by Editor(s). Dr. Richard L. Slaughter, Wayne State University, USA 